\title{
The Investigating Corruption Practises and Asset Misuse by the Employees of Project Laborer Services
}

\author{
Mohammad Farid Wajdi Fahmi *, Mohammad Nizarul Alim, Alexander Anggono \\ Economy and business faculty of Trunojoyo University, Madura, St. Raya Telang PO.BOX 2 Kamal, Bangkalan, \\ Madura, Indonesia
}

*Corresponding Author: Mohammad Farid Wajdi Fahmi, Economy and business faculty of Trunojoyo University, Madura, St. Raya Telang, PO.BOX 2 Kamal, Bangkalan, Madura, Indonesia

\begin{abstract}
This research is aimed to explore the determinants that influence the corruption practises and asset misuseby the employees of Project Laborer Services. This research using a qualitative approach with a case study method. Sources of data in this research consisted of primary data such as interviews with selected informants and observation results, the secondary data which is the result of observation in the field. The result of the research shows fraud in accounting practices committed by employees in the office and field such us (1) corruption (gratification, bribery, embezzlement in position, extortion, fraudulent act); and (2) misappropriation of assets like (the treasury theft, the fraud expense, cost claim reimbursement, cost fraudulant reimbursement, payroll fraud). Determinants that affect the practice of corruption and misuse of assets by employees in the form of an internal control system, leadership style, fairness of compensation, organizational culture.
\end{abstract}

Keywords: Corruption, Misappropriation of Assets, Diamond Fraud, GONE

\section{BACKGROUND OF STUDY}

Corruption is an act of any person categorized as being against the law, committing an act of selfenrichment, by abusing the authority, opportunity or any means available to anyone because of their position or position which can harm the country's finances or economy. Misappropriation of assets is fraud involving the assets of an entity, so it refers to theft by employees and other internal parties in an entity.

The project laborer services is one of the agencies that has the function of supervising the repair and maintenance of road pavement conditions, bridge repair and maintenance carried out by partners. The forms of supervision are carried out to obtain high-quality and high-quality work results so that they can function as roads and bridges in accordance with their designation for the wider community.

(De Jong et al., 2009)argues that "The public works sector or construction is the most corrupt sector in the world". The most common forms of corruption in the construction sector are reducing or even eliminating items, volumes, tools that have been listed in the work contract, but in their implementation in the field there is no use of these items, the impact is felt by the wider community because they cannot enjoy the results of public sector work with good and high quality.

Corrupt practices are generally carried out by partners with the aim of obtaining the maximum benefit from the contract value, by reducing or eliminating items that could be manipulated, but this corrupt practice will not occur if the board of directors performs the supervisory function properly, which is precisely what It often happens in the field that not, infrequently individual employees of the board of directors also "play" to get additional rupiah beyond the state compensation they have received.

This study explores forms of corruption and misuse of assets by individual employees at the project laborer service and analyzes them with the diamond fraud theory and the GONE theory, these theories were chosen by researchers because they are considered suitable theories to study the causes that make those individuals. Employees engage in corrupt practices and misuse of assets, so that after reviewing these theories it can be concluded what determinants lead to corrupt practices and misuse of assets by unscrupulous employees in the project laborer service. 
Previous studies that have examined corruption in the construction sector include research by(De Jong et al., 2009)which found that the corruption sector is the most corrupt sector in the world, research by(Locatelli et al., 2017)found that the public sector and procurement of large projects are ideal to causing corrupt practices. The difference between this study and previous research lies in tracing the determinants that influence someone to practice corruption and abuse of assets in the construction / public works sector board of directors.

Based on the background described above, the formulation of the problem in this study is how the practices of corruption are and misuse of assets carried out by employees at the project the project laborer services? The purpose of this study is to investigate corruption and misuse of assets committed by project workers at the project laborer services.

\section{METHOD}

This study uses a qualitative approach with a case study method, which is an approach that aims to understand a phenomenon that has been experienced by research subjects by describing it in the form of words in a special natural context(Moleong, 2017). The writers choose case study research because it can describe human life and actions specifically in a particular location. In addition, it is suitable for a study where the researcher has obtained an overview or initial data about the problem to be analyzed in the study.

This research is a descriptive type of research, namely research conducted with the aim of describing or providing a systematic and accurate description of the facts about the population based on the facts of the research results at the research location and presented as actual it is. The data collection technique is done by combining (triangulation), namely interviews, observation, and documentation related to this research.

This study used in-depth interviews, namely structured interviews using interview guides with the following points: (1) What forms of accounting fraud have occurred; (2) The modus operandi of accounting fraud; (3) The object of the perpetrator who committed accounting fraud.

\section{RESUlT AND DISCUSSION}

Based on observations and interviews with informants who have been selected in this study, it is found that there are forms of corrupt practices and misuse of assets by unscrupulous employees in the office or in the field, employees engage in corrupt practices and misuse of assets.

\subsection{Corruption Practices by Some Employees in the Office}

\subsubsection{Gratification}

The practice of corruption in the form of gratification often occurs in the scope of construction work, usually carried out by partners, in this case the contractor against the board of directors, the act of gratification is carried out with the aim that when the project work is taking place, the board of directors, conducting supervision is not too strict and can provide a leeway to the contractor, The practice of gratification was found to have occurred in the laborer project services based on the recognition of 'MLY' (initials).

"This year, our boss asked the contractor at the beginning of the work for 5\% of the contract value, if before this boss, the previous boss asked him when there was 'Eid or New Year, if the previous bosses asked for the same before the start of the work and what percentage of the contract value, but not more than 5\%, so if you get a bad contractor too, sometimes our bosses can't get strict when it is implemented, because from the start we have got it from partners"

Corrupt practices carried out by some employees in the laborer project services include corrupt practices in the form of gratuities, namely activities to accept, ask for, or commit bribery(Lambsdorff et al., 2004). This act of cheating arises because it utilizes a capability element as a leader in an agency, so that the variable that affects is the variable of leadership style. The culture of corruption that often occurs in government institutions is initially influenced by corrupt leaders who will then be followed by junior officials within the institution(De Jong et al., 2009).

\subsubsection{Bribery}


Corrupt practices are the form of giving bribes to employees who have the authority to recruit new recruits to the laborer project services. This kind of practice occurs when a person in power manipulates the public procurement process to give to friends or relatives privileged access to public contracts for goods, jobs, and services(Hamilton, 2010). Forms of bribery are known to occur in the laborer project services based on a confession from 'AS' (initials).

"Here, the model is like a political dynasty, so there is a term for this office, the office is 'S', just look at all those 3 children here, not yet coming to their nephews and adopted children, even it was becoming the noisy talk when they wanted to put the wife into the office whose children were already working here, after that they intended to put his youngest son here, he is close to the employment section of $M r$. ' 'H', see last year a new employee entered the general administration section called ' $F$ ', this new employee paid 40 million to enter, 8 million for $M r$. ' $H$ ' , the rest went to $M r$. 'S' pocket. Before he even put his neighbor into the offices, it was only 30 million cheaper"

The statement from 'AS' was also strengthened by a statement from 'HMR' as a staff member that the practice of bribery occurred in the laborer project services, but this time with different actors along with different modus operandi, namely by committing bribes to include relatives as team members of job supervisor consultant.

"Our leadership previously included relatives in the supervisory consultant team on road repair work, but this has been a finding and the supervisory consultant has received a fine for including members who do not match their specifications, so that for the following year his relatives are not included in the supervisory consultant team because the consultants themselves who refused, finally he entered the contractor as an executor in the repair work"

The practice of bribery allows an incompetent person to work even though he uses another person's name and title in a road repair work package contract. So, it has an impact on the quality of the results of the road repair work he does.

\subsection{The Misuse of Asset Practices by Some Employees in the Office}

\subsubsection{The Treasury Theft}

One form of asset misuse that occurs in the laborer project services is treasury theft, this practice occurs because of the element of opportunity in a condition that allows someone to commit fraudulent practices, this form of fraudulent practice occurs based on the recognition delivered by 'RP' (initials).

"If the big boss is a guy, usually the one who has the treasury account for shopping should be me every year, I am free to spend the contents of that account on personal purchases such as buying clothes, cosmetics, and other women's needs, the most important thing is that the use is not excessive and reasonable every month, because I hold the account, so I am free to process office spending data according to my wishes, but this year I can't do it anymore because the big boss is a girl"

The fraudulent practice carried out by 'RP' by using office assets in the form of a shopping treasury account to buy personal needs such as clothes, cosmetics is a form of theft against the institution's treasury account, this kind of practice occurs because of an element of opportunity in the form of a position as financial staff and its closeness to the leadership of the institution by utilizing gender.

\subsubsection{The Fraud Expenseses}

Other asset misuse practices carried out by some employees in the office are fraudulent expenses, namely forms of fraudulent acts such as manipulating notes or receipts when shopping for office stationery, gasoline, and eating and drinking, this kind of practice aims to get personal benefits. Fraudulent expenditure fraud was carried out by some staff employees as conveyed by 'AM' in the following:

"Usually for the needs of shopping for stationery every month, I take some person to buy stationery, but people often ask for blank notes to the shop where they buy it, and this kind of practice is not only about stationery but also for gasoline and eating and drinking"

The practice of misusing institutional assets by manipulating expenditure notes or receipts for office supplies is carried out by some employees who have the authority to purchase these items, this action is often carried out because of the ease for the person to carry out and is supported by the weakness of the institution's internal control system. Other forms of fraudulent spending are also carried out by 
manipulating fictitious official travel expenses, namely in the form of disbursement of official trips but no official trips are made, employee names are on the list of invitations for activities, but the person concerned does not leave, but official travel is still disbursed only for waste of budget, as conveyed by 'RP' (initials).

"Every year the guy with ' $N$ ' often asks for disbursement for survey activities to bridges in the city of ' $S$ ', even though there is no official invitation, and there is no documentation of his official activities, but he still insists on asking for it to be disbursed, even though for the position it seems there is no budget for the bridge survey official trip because it has become its main function"

The practice of fraud by manipulating fictitious official travel by ' $\mathrm{N}$ ' employees is a form of fraudulent spending asset misuse, this action can be done because it takes advantage of their proximity to 'RP' employees as financial staff, if it is linked to the diamond fraud theory, then the determinant of opportunity which is the background for the occurrence of fraudulent acts by the person ' $\mathrm{N}$ '.

\subsubsection{Cost Claim Reimbursement}

Another practice of misuse of assets is in the form of reimbursement on cost claims that often occur in replacing office equipment such as air conditioners, vehicle batteries. Because items like this often get damaged, there is always a gap for the person to maximize every opportunity that exists to make it an act of fraud. As stated by 'AM' (initials).

"The air conditioner in the engineering room is often damaged, it has only been repaired for two weeks, so the air conditioner is often serviced, and the repairmen have to bring it from their hometown, whereas in Kek Lessab Regency itself there are many better AC repairmen. In total you can even buy a new air conditioner, but fortunately if you just 'play' the AC, it's not much to earn but it's still being done".

This practice is misusing assets by replacing cost claims for repairing office equipment. This kind of practice occurs because there is an opportunity and convenience for the person to commit acts of fraud and is supported by the weak internal control system in the institution.

\subsection{Corruption Practices by Some Employees in the Field}

\subsubsection{Embezzlement in position}

The practice of embezzlement in positions carried out by some employees in the field arises when there is a gap for the person to do so. One form of embezzlement is taking part or all of thebudget for the work subdivision. The form of embezzlement carried out by irresponsible employees of the project laborer services as conveyed by 'IY' (initials).

"In every project, there must be a security fund, the objective of which is to smoothen the running of a project, such as the 2018 project, there is an allotment for security but it is corrupted by individuals from our own place, we found out about it during the 2019 project yesterday when we were as usual at the beginning of each project year. Coordinating with security, the head of this "P" institution asked for a quota for him, and his agency for 2018. Even though this fund is clearly available and budgeted for any expenses, but the nominal is quite large, but how come it has not arrived at its place, obviously this has been corrupted by those who brought the funds and the suspicion still leads to the person who brought it".

The practice of embezzlement in office is also carried out on project items such as ex-disassembled bridges and excavations which are easy for some employees to carry out. The form of embezzlement of project items is as told by one of the informants, 'ASW' (initials).

"I myself interrogated the person at that time. What happened was when the office was still quiet, it was true that there was an instruction from boss 1 to bring the pieces of it. However, the instruction was to bring to the head office not to junk, he excused that it was closed because it was night, so it was just turned into a junk, but after I cross-checked it with boss 1, he thought it was deflected back to the office again, not to junk. This case became crowded after BMN's findings when evaluating state assets, based on mutual agreement that the person must replace it with the same nominal value when the goods were sold, this case has ended in a peaceful way, because the person and his gang have replaced them with the same nominal value." 
The practice of embezzlement in office occurs because of the ability for the person to commit his actions so that the element of ability encourages the person to commit his actions, but from his motive for committing the act the perpetrator has been acknowledged that there is an element of need, namely to meet the needs of his child and wife at home.

\subsubsection{Extortion}

The practice of corruption in the form of extortion was also carried out by unscrupulous employees of the project laborer services with the initials ' $\mathrm{N}$ ' against several parties, this practice of extortion was carried out by utilizing their position. As the explanation of 'ASW' (initials) as coordinator of the following field supervisors regarding the practice of extortion carried out by the person ' $\mathrm{N}$ '

"In 2018 last time, individuals lobbied the bosses and deputy bosses to provide sub-work on Environmental impact assessment to him, the contractor had not actually dealt with the person, and the contractor tended to use the services of other parties who were more competent, and the price difference was almost twice as expensive as the one. ' $N$ '. Maybe because he felt disappointed that the contractor was canceled unilaterally, the ' $N$ ' immediately blackmailed the contractor with reasons of compensation, the contractor agreed because the nominal value was not too large".

Extortion carried out by some employees with the initials ' $\mathrm{N}$ ' has also been committed against other parties.

"It happened that a truck driver crashed into one of the bridges on our section, so that the para-vets and the bridge fences were damaged, the driver wanted to take responsibility for his mistakes, but because according to the SOP, the driver's office had to meet $M r$ 'S', on his recommendation, he The driver has to confirm to the person ' $N$ ', I feel something is wrong here because the one who owns the area of the " $W$ " is not " $N$ ", but the answer is $M r$ ' $S$ ' because the ' $N$ ' knows a lot of the policemen there so let it be his business easy, it turns out that the driver was targeted at 20 million so that his business was sorted out, after I hospitalized the damaged bridge, it turned out that the cost of replacing the damaged bridge element was only around 5 million"

The act of extortion carried out by an employee with the initials ' $\mathrm{N}$ ' was carried out more than once against different victims, the person ' $\mathrm{N}$ ' always repeated his acts of cheating without any deterrent effect, this was due to the element of exposure, namely the disclosure or weak enforcement of punishments at the project laborer services. And there is rationalization or justification from their superiors that what they have done has received approval from the leadership of their institution. The act of extortion describes the crime of obtaining money or some other valuables by the abuse of an authority or position.

\subsubsection{Fraudulent acts}

Fraudulent acts that are often carried out by some employees in the Project laborer services, namely corruption by manipulating work records, acts of corruption like this are common in every job, all work items can be manipulated by some employees who have the ability to do so and are supported by open wide opportunities for individuals to commit fraudulent acts. The forms of fraudulent acts by some employees of the project laborer are carried out on grass swipe work items. This fraudulent act was conveyed by 'MAR' (initials).

"For grass swipe, if the foreman is still the ' $N$ ', it is just as messy, the job is not available, there is no work photo, but the job registration is complete, as a result every month the grass swipe is always absorbed, I have been to the field directly, and there really was no swipe work in the field.".

Fraudulent acts are not only committed by employees of the project coolies office, but are also often committed by partners who are contractors for road repair and maintenance work, fraudulent acts by partners can be in the form of not using tools as previously stated in the contract, absorbing against work even though the job has not been completed or has been wrongly executed. Even though the fraudulent act was committed by the partner, the board of directors, in this case the project laborer services, were also indicated as having committed fraudulent acts due to negligence in overseeing road repair and maintenance work. This fraudulent act has been raised by 'SDC' (initials).

"Some cheating has occurred, such as in this year's package for Cold Milling Machine (CMM) work, in the field they do not use CMM tools, but in the contract they are required to use CMM tools, but in 
the field we still write using tools even though the process is manual, and later. The results of work in the field of the administration that does back up the work for withdrawing MC every month".

Fraudulent acts committed by supervisors, namely deliberately neglecting to allow fraudulent acts committed by partners, without exercising their authority as a supervisor who has the right to prevent fraud, omission occurs due to several factors, usually the fraud that occurs is systemic, meaning that the supervisor the field allows fraud that occurs because the system above it also commits fraud, so that if he becomes the one who opposes the occurrence of fraud, he will be kicked out by a system that is deeply rooted.

\subsection{The Misuse of Asset Practices by Some Employees in the Field}

\subsubsection{Cost fraudulent reimbursement}

The practice of misuse of assets in the form of fraudulent reimbursement claims is often carried out by employees who work in the field, because the weakness of the organization's internal control system is also a contributing factor to the fraudulent act of claim reimbursement committed by some project workers, and is supported by the neglect by superiors on fraudulent practices can also be a factor in the emergence of fraudulent practices, such as the following narrative for the field foreman with the initials 'SRY':

"When I did the maintenance of the bridge, I painted it, bro, but the cost is to use the cash receipt system first, so use my money first, when the job is finished then I ask for a change from $M r . "$ " $"$ ", now when I ask for work costs plus payment I deposited the notes to him, well he told me that Mr. "N" also asked for the cost of painting the bridge and $M r$. "S" had already paid it to Mr. "N", I complained, bro, I worked on painting the bridge, why? The one who receives the payment is $M r$. "N", maybe because he doesn't want to be busy, sir " $S$ " is still paying me too, sir, because I am the person of Mr. " $A$ " who is clearly the leader here, while $M r$. " $S$ " is only the representative, but the money in gold " $N$ " doesn't know whether to reverse it or not, most likely not bro, because the two people are the same".

The practice of misuse of assets with fraudulent claims for reimbursement of costs committed by person ' $\mathrm{N}$ ' is in the form of manipulating superiors by asking for painting work fees even though they are actually working on someone else, resulting in two expense accounts to pay for painting costs for one job. The act of cheating by the person ' $\mathrm{N}$ ' reflects poor internal control in the institution, as well as the carelessness of the leader when he costs twice the painting fee, even though the person does not do painting work at all but receives payment for painting work.

\subsubsection{Payroll fraud}

The practice of fraudulent wages is usually carried out by the field foreman in charge of supervising work items in road repair and maintenance work, work items such as grass swipes, patching (asphalting), always being an opening for some employees to commit fraud, such as the explanation 'MR' (initials).

"If ' $N$ ' just goes to pavement once he has to receive one million from $M r$ 'S' because the location is further away in the city of Bahari, then the workers use 7 people, even though in reality he only uses 4 workers, how much profit The ' $N$ ' is for asphalt only a day, if in a week he paves up to 5 times, how much benefit, compared to my team whose workers are only limited to 5 people and operational for asphalt is also far from what ' $N$ ' received.

Actions of accounting fraud, both corruption and misuse of assets, always involve an employee with the initials ' $\mathrm{N}$ ' as the perpetrator of fraud. This happens because the person ' $\mathrm{N}$ ' has a position as a field foreman also has a close relationship with $\mathrm{Mr}$ 'S', namely as the number two person in the Project $\mathrm{B}$ laborer department. The factors include rationalization from superiors, weak internal control systems, exposure in the form of less strict punishment.

\section{CONCLUSiON}

From the results of interviews conducted with informants who have been selected as sources in this study, both from employees in the office and employees in the field, it can be concluded that acts of accounting fraud committed by some project workers.

Forms of corruption that are often carried out by unscrupulous employees in the project laborer services, such as: embezzlement in office; Extortion; Gratuities; Bribery Bribing; Cheating. 
Forms of misuse of assets that are often carried out by unscrupulous employees in the project coolies office, such as: Cheating in payroll; Cash theft; misuse of non-cash assets

The practice of accounting fraud committed by unscrupulous employees if it is related to the diamond fraud theory and GONE theory, then the elements of rationalization, opportunity,greed, and exposure are the most likely to lead to acts of accounting fraud by project workers.

The determinants that affect the act of accounting fraud committed by individual employees in the project laborer services include: internal control system, superior leadership style, suitability of compensation, organizational culture.

\section{SUGGESTION}

Providing strict punishment for the perpetrator who is proven to have committed an act of accounting fraud, because it has harmed the institution and also the state, by giving strict punishment can break the chain of accounting fraud by other unscrupulous employees.

Conduct regular and routine supervision of state assets such as project items that are easy to be embezzled by fraudulent employees.

\section{REFERENCES}

[1] De Jong, M., Henry, W. P., \& Stansbury, N. (2009). Eliminating corruption in our engineering /construction industry. Leadership and Management in Engineering. https://doi.org/10.1061/(ASCE)15326748(2009)9:3(105)

[2] Hamilton, D. K. (2010). Patronage in Illinois: The political subjugation of public administration. Review of Public Personnel Administration. https://doi.org/10.1177/0734371X09360851

[3] Lambsdorff, J. G., Taube, M., \& Schramm, M. (2004). The new institutional economics of corruption. In The New Institutional Economics of Corruption. https://doi.org/10.4324/9780203413920

[4] Locatelli, G., Mariani, G., Sainati, T., \& Greco, M. (2017). Corruption in public projects and megaprojects: There is an elephant in the room! International Journal of Project Management. https:// doi.org /10.1016/j.ijproman.2016.09.010

[5] Moleong, L. J. (2017). Metodologi Penelitian Kualitatif (Edisi Revisi). In PT. Remaja Rosda Karya.

Citation: Mohammad Farid Wajdi Fahmi, Mohammad Nizarul Alim, Alexander Anggono. "The Investigating Corruption Practises and Asset Misuse by the Employees of Project Laborer Services" International Journal of Managerial Studies and Research (IJMSR), vol 8, no. 9, 2020, pp. 1-7. doi: https://doi.org/10.20431/23490349.0809001.

Copyright: (c) 2020 Authors. This is an open-access article distributed under the terms of the Creative Commons Attribution License, which permits unrestricted use, distribution, and reproduction in any medium, provided the original author and source are credited. 